\title{
Failure to Analyze Signal
}

National Cancer Institute

\section{Source}

National Cancer Institute. Failure to Analyze Signal. NCI Thesaurus. Code C63196.

Problem with the device not analyzing a signal. 